the pyrophosphates and the common phosphates, as they are usually denominated, but which the author proposes to designate by the terms bibasic and tribasic phosphates. Arsenic acid forms only one class of salts; but that class is anormal; every member of it containing three atoms of base to one atom of acid like the common, or tribasic, phosphates. These anormal classes of phosphates and arseniates are the only known salts to which the ordinary idea of a subsalt is truly applicable : all other reputed subsalts being probably neutral in composition, as has been shown by the author in the case of the sub. nitrate of copper; for they all bear an analogy to this salt in their small solubility and other properties, while they exhibit little resemblance to those classes of phosphates and arseniates which really possess more than one atom of base."

\section{The Gresham Lecturers}

ON December 9, 1836, the Court of Common Council of the City of London considered a report which had been presented on the question of trans. ferring the Gresham Lectures from the small incom. modious room at the Royal Exchange to the City of London School. In its report of the proceedings, The Times said: "There are seven lecturers under the will of Sir Thomas Gresham, each of whom is paid a liberal salary for occasionally lecturing upon scientific and other topics, in an obscure apartment in the Royal Exchange, and the very spacious and commodious school endowed by the Corporation being almost finished, a committee was appointed to consider and report the best means of deriving some public advantage from the employment of the lecturers. The Corporation have been for some time endeavouring to obtain the consent of the gentlemen who derive the pecuniary emolument from these appointments to transfer their exertions to some more enlarged sphere of action in the city; but hitherto all attempts to induce them to leave the old station, whose walls have so long witnessed their abortive labours, have been ineffectual."

The lecturers, with one exception, objected, maintaining among other things that the removal of the lectures to the School "would not be advantageous to the public, but on the contrary would be injurious to the foundation of the Gresham institution, by attaching it to the school and destroying its independence". The Times of December 13 contained a letter from one of the lecturers and a copy of the resolutions passed by himself and the others on November 17. One of these ran "That, in the opinion of the lecturers, there can be no want of funds to maintain or carry out the Gresham lectures according to the founder's intentions, it appearing from the report of the Charity Commissioners of 1821 that the yearly income of the Gresham estates then amounted to $£ 6,080$, while the yearly payments, on account of

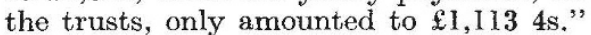

The Gresham professorships of "divynitye, as. tronomy, musicke, geometry, law, physicke and rethoricke" date from 1595, Henry Briggs being the first professor of geometry. From 1597 until 1768, the lectures were given in Gresham's house in Bishopsgate Street. They were then given in the Royal Exchange until that building was destroyed by firo in 1838 . In 1843 a special building was erected in Gresham Street, this being replaced in 1913 by the present College. The chairs of geometry and astronomy are the oldest in Great Britain.

\section{Societies and Academies Dublin}

Royal Irish Academy, November 9.

Norman Harris : Petrological study of the Port. rush sill and its veins. The Portrush sill has been mapped on the 25 -in. scale, particular attention being paid to variations within the sill itself, and to the different types of veins and their relationship with the hornfelsed lias of the roof. The bulk of the intrusion is coarsely mottled olivine-dolerite; then passes marginally into a fine-grained intergranular type. Micrometric analyses show that the proportion of olivine and iron-ore increases with depth. Chemically the average rock corresponds to the Hebridean Plateau-Magma-Type. Various types of hornfels and their mineral developments are described. Several occurrences have been found of veins of mobilized hornfels which pass downwards into the sill from the roof. Other veins and sheets within the sill are shown to comprise metasomatized hornfels and also a variety of synthetic rocks which are referred to the action of the magma and its emanations on included rafts of hornfels. The absence of veins in the Lias roof and the capacity of the hornfels to inject the olivine-dolerite indicate that the hornfels was under internal compression, presumably due to expansion, while the upper part of the sill was contracting and under internal tension. A later hydrothermal stage is represented by widely distributed calcite-chlorite-zeolite veins. Five types of pyroxene have been recognized in the rocks in. vestigated. Analyses are given of two of the pyroxenes : common augite and pigeonite.

\section{Paris}

Academy of Sciences, November 9 (C.R., 203, 901$960)$.

AlFred Lacroix : The meteorites (æroliths) found in the Tanezrouft (Western Sahara). The two fragments found appear to have fallen at the same time, very recently. From the mineralogical and chemical examination, these meteorites are pliosideriferous chondrites.

Jean Cabannes and Jean Dufay : Regularities in the spectrum of cometary nuclei.

MARC KRASNER : Multiplicative representation in the body of -adic numbers relatively Galoisian.

FRÉDÉRIC ROGER: Taylor's formula and the differential geometry of ensembles.

Casimir Kuratowski : Projective ensembles and the operation $(A)$.

P. Erdös and Erwin Feldheim: The mode of convergence for the Lagrange interpolation.

RENÉ LAGRANGE : The theorems of addition of Legendre functions.

Bohuslav Hostinsky : The superposition of two sinusoids.

DANIEL BARBIER: The emission of electrons by the sun and its relation with terrestrial magnetic phenomena.

LÉopold EsCANDE and Georges Sabathe : Errors produced by the inclination of the trajectories in calibrations carried out by means of hydrometric screws with counting gear. If the axis of the rotating screw is not in the same direction as the moving water, serious errors are produced. For an inclination of $20^{\circ}$ the error is ten per cent, and this error increases rapidly with the angle. 
Jean Louis Destouches: The generalization of the Lorentz transformation for a system of corpuscles.

JACQUES SolomoN : Diffusion of light by neutrons.

Mule. Suzanne VerL : Electrometric potential and constitution of electrolytes.

Pierre Barchewitz: Study of the absorption spectra of benzene and its derivatives in the near infra-red (6000-9500 A.). A table of results for ten compounds is given: the figures confirm the views of $\mathrm{R}$. Freymann on the influence of certain groups on the position of the bands $(\mathrm{CH}=)$.

MLAden PaIć: Absorption spectra in the ultraviolet of coproporphyrin and of some of its metallic complex compounds.

LÉON JACQUÉ : Mechanical properties of steels treated with hot hydrogen under pressure. Ordinary steels under this treatment are decarbonized and show a loss in mechanical strength. But steels with 3-6 per cent of chromium, $0 \cdot 5$ per cent of molybdenum, no nickel and low carbon retain their mechanical properties and hence are suitable for work at high temperatures under pressure of hydrogen.

JEAN WYART : The crystalline network and macles of leucite.

Gilbert Mathieu : The principal bands of phtanite of the Brinoverian of Vendée.

MarCEL Thoral : Age and fauna of the Ordovician schists of Cabrières (Herault) known as 'Asaphus schists'.

Alexis Lambert : Presence of the Senonian in the Djurjura chain.

JEAN LACOSTE : Remarks on some structural characters and on certain aspects of petroleum geology, in two analogous regions, the Subcarpathians and the Sud-Rif regions.

Charles BoIs : The importance of the long waves and the depth of focus in earthquakes.

Marius Chadefaud: The chondriosomes and plastids of Caulerpa (Green Algæ).

A. and R. SARtory and J. Meyer : Influence of a partial or high vacuum on the growth and morphology of some lower fungi.

MAX LAFON : Weight evolution of the organs in mice deprived of lysine.

Paul Durand, Paut Giroud, Edouard Larrive and ANDré Mestrallet : Susceptibility of animals to the virus of the maladie des porchers.

\section{Geneva}

Society of Physics and Natural History, October 22 .

F. Chodax and G. CARrisson: The effect of sodium mono-iodoacetate on the respiration of the yellow Staphylococcus. The authors give measurements of the inhibitive action of sodium mono-iodoacetate on the respiration of Staphylococcus aureus. This is already apparent at a concentration of $M / 50,000$ of the reagent, and is reduced to one half at a concentration of $M / 1,000$.

P. Rossier: (1) The approximate expression of the colour index as a linear function of the inverse of the effective temperature of stars. A development, in series, of an expression obtained in a general theory of the index, gives sufficient expressions in some cases where the accuracy of the observations is not very great. (2) Observations of the 1936 comet. Photo- graphic observations of July 19 and $23,1936$. Spectrographic observation of July 23. (3) Spectrographic observations of Novæ Herculis, 1934 and Aquilæ, 1936. The loss of brightness of Nova Herculis appears to have influenced the continuous spectrum and most of the emission lines, excluding those of ionized oxygen. The spectrum of Nova Aquilæ, 1936, shows the hydrogen line and the line at $4640 \mathrm{~A}$. characteristic of novæ in the form of wide emission lines.

B. Hochreutiner : Announcing the republication of the "Flora orientali" of Edmond Boissier, of vol. 6 of de Candolle and the issue of a new periodical, Le Boissiera. Part 1.

\section{Moscow \\ Academy of Sciences (C.R., 3, No. 4, 1936).}

E. Voronovsky: A minimum problem in the theory of sequence of moments, and the evaluation of the polynome (2).

S. M. RYTov: Diffraction of light by ultra-sound.

V. V. WEREDNIKOV : Influence of soil capillarity on the oozing of water with free surface.

P. P. BuDNmov and E. I. KREč : Evolution of sulphur oxides from calcium sulphate by means of chlorine, in the presence of catalysts, for simultaneous production of hydrochloric and sulphuric acids (2). Behaviour of different modifications of silica towards chlorine at high temperatures.

V. S. Sadikov and A. G. Pesina : Autoclave splitting of the non-extractable portion of beef by means of an aqueous solution of lithium carbonate.

T. T. Demidenko, A. A. Kulkes and V. P. Popov : Colloids in beef correlated with soil liming.

A. Schwartz and S. F. Kuzmin: The potato in its genetic aspect. (2) Variability of the protein content in the interspecific hybrids Solanum phureja $\times$ S. rybinii.

I. A. Filippenko : Physiological characteristics of vernalized and non-vernalized winter wheat.

N. Bezвononko: The Tchernigov-Donetz Basin zone of volcanism, and the geochemical province connected with it.

$$
\text { (C.R., 3, No. 5, 1936). }
$$

M. Jaltunovikaja : A problem of interpolation.

N. S. SMIRnov: Existence theorem of non-linear integral equations.

B. V. Numerov : Compilation of a fundamental catalogue of right ascensions.

G. Duвošñ : One particular case of motion in the resisting medium with a variable mass.

V. Fabrikant : Contribution to the problem of the disappearance of spectral lines in strong electrical fields.

L. G. Gindin, I. I. Torsujev and W. A. KazA. Kova : Behaviour of sulphur solutions, and of a series of organic compounds of sulphur in saturated carbohydrates towards metals.

M. P. Volarovič and A. A. LeontJera : An investigation of the elasticity of some molten rocks.

J. V. Rakitin : Controlling the ripening of the Japanese persimmon.

M. I. SALtykovskiJ : Cold resistance of the first generation of wheat hybrids.

A. N. Družrnin : The problem of structure and the evolution of the elbow joint of Mammalia. 